\title{
Dorello's Canal for Laymen: A Lego-Like Presentation
}

\author{
Haim Ezer, M.D. ${ }^{1}$ Anirban Deep Banerjee, M.D. ${ }^{1}$ Jai Deep Thakur, M.D. ${ }^{1}$ Anil Nanda, M.D., F.A.C.S. ${ }^{1}$ \\ ${ }^{1}$ Department of Neurosurgery, Louisiana State University Health \\ Sciences Center, Shreveport, Louisiana \\ J Neurol Surg B 2012;73:183-189.

\begin{abstract}
Address for correspondence and reprint requests Anil Nanda, M.D., F.A.C.S., Professor and Chairman, Department of Neurosurgery, Louisiana State University Health Sciences Center at Shreveport, 1501 Kings Highway, P.O. Box 33932, Shreveport, LA 71130-33932 (e-mail: ananda@lsuhsc.edu).
\end{abstract}

\begin{abstract}
Objective Dorello's canal was first described by Gruber in 1859, and later by Dorello. Vail also described the anatomy of Dorello's canal. In the preceding century, Dorello's canal was clinically important, in understanding sixth nerve palsy and nowadays it is mostly important for skull base surgery. The understanding of the three dimensional anatomy, of this canal is very difficult to understand, and there is no simple explanation for its anatomy and its relationship with adjacent structures. We present a simple, Legolike, presentation of Dorello's canal, in a stepwise manner.

Materials and Methods Dorello's canal was dissected in five formalin-fixed cadaver specimens (10 sides). The craniotomy was performed, while preserving neural and vascular structures associated with the canal. A 3D model was created, to explain the canal's anatomy.

Results Using the petrous pyramid, the sixth nerve, the cavernous sinus, the trigeminal ganglion, the petorclival ligament and the posterior clinoid, the three-dimensional structure of Dorello's canal was defined. This simple representation aids in understanding the three dimensional relationship of Dorello's canal to its neighboring structures.

Keywords

- Dorello's canal

- anatomy

- 3D

- skull base

Conclusion Dorello's canal with its three dimensional structure and relationship to its neighboring anatomical structures could be reconstructed using a few anatomical building blocks. This method simplifies the understanding of this complex anatomical structure, and could be used for teaching purposes for aspiring neurosurgeons, and anatomy students.
\end{abstract}

Dorello's canal was described for the first time, by Gruber, in $1859 \mathrm{AD}$, as an osteofibrous canal at the apex of the petrous bone, containing the abducens nerve and the inferior petrosal sinus. $^{1,2}$ In 1905, Dorello, and later in 1992, Vail, described Dorello's canal's anatomy. ${ }^{2-4}$ Dorello's canal was noted to be clinically important in understanding sixth nerve palsy. ${ }^{2}$ In the recent century, Dorello's canal anatomy was further studied, and the clinical implications turned toward its relevance to skull base surgery, mostly for petroclival lesions.
Umansky et al were the first to perform a microanatomic study of the Dorello's canal, and reported it in 1991., Umansky's study contributed a lot to the understanding of the canal's anatomy. They presented microscopic measurements of Dorello's canal's anatomic elements and defined its complex relationship to the cavernous, basilar, and inferior petrosal sinuses.

The authors further discussed the controversies surrounding the canal's definition and proposed their own opinion in received

November 10, 2010

accepted after revision

March 6, 2011

published online

May 7, 2012
Copyright (c) 2012 by Thieme Medical Publishers, Inc., 333 Seventh Avenue, New York, NY 10001, USA. Tel: +1(212) 584-4662.
DOI http://dx.doi.org/ $10.1055 / \mathrm{s}-0032-1311753$. ISSN 2193-6331. 
this subject. Since then, many authors contributed a lot to the anatomic elucidation of this region. ${ }^{1,4-9}$ However, the threedimensional (3D) anatomy of this canal is very complex and difficult to understand: there is no simple explanation for the structure of this canal and its relationship with adjacent structures. The petrous apex, with its adjacent structural relationships, was actually termed as one of the most complex regions of the skull base. ${ }^{7}$ In contrast to the surgical need for a detailed knowledge of the microanatomy of Dorello's canal, only a few references to this structure could be found in the literature. ${ }^{2}$ We present a simple, Lego-like presentation of
Dorello's canal anatomy, in a stepwise manner, using few known anatomical landmarks, as building blocks.

\section{Methods}

Dorello's canal was dissected in five formalin-fixed cadaver head specimens (10 sides). The arteries were perfused with red silicone and the veins with blue silicone, in a manner described earlier. ${ }^{10}$ The specimens were dissected, with the aid of an operating microscope, to expose the petrous pyramid, the sixth nerve, the cavernous

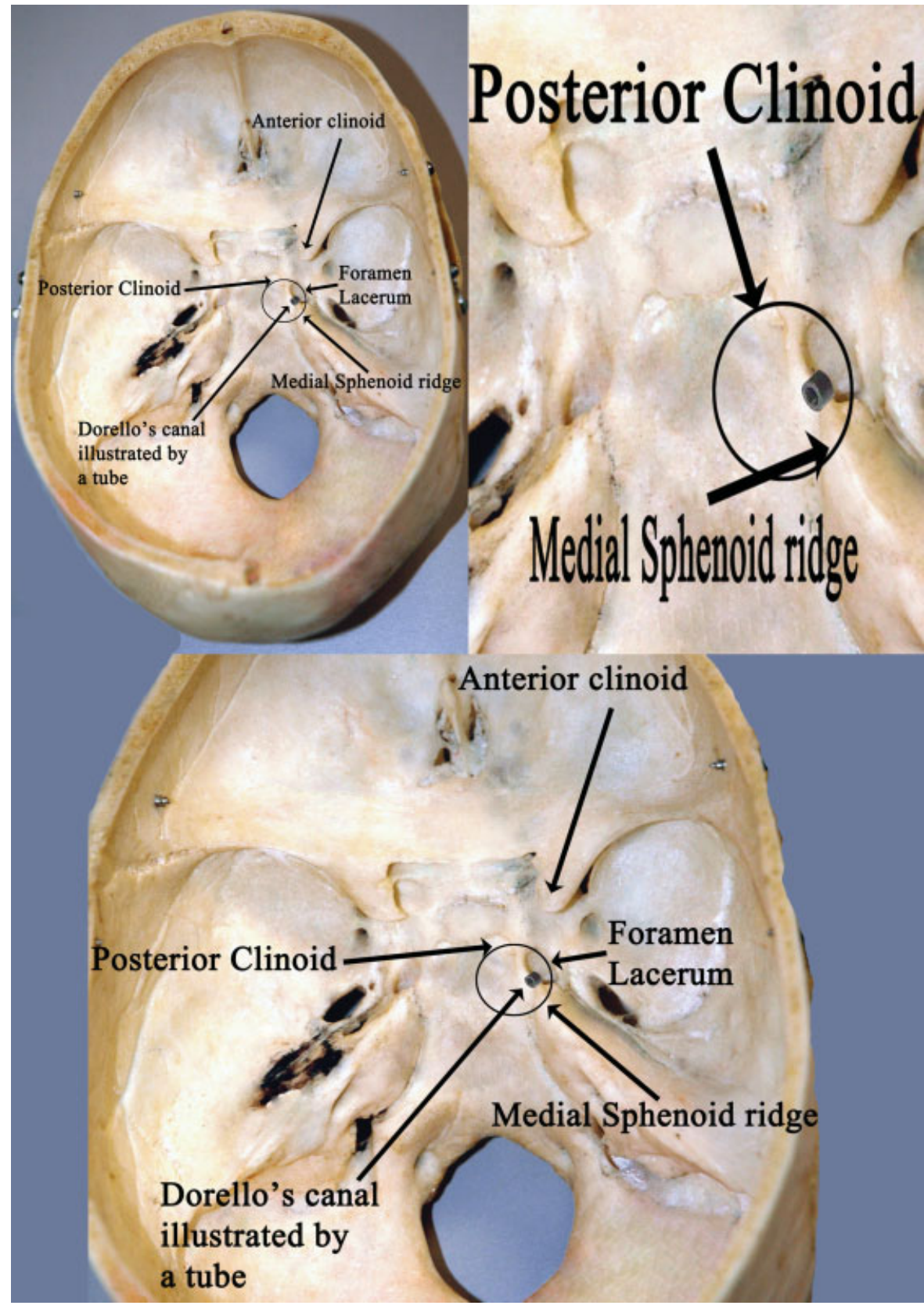

Figure 1 (A) A superior view of the skull base, with special attention to the area between the medial sphenoid wing and the posterior clinoid (Black circle), and Dorello's canal illustrated by a plastic tube. (B) An enlarged view of the same image, emphasizing the proximity of Dorello's canal to the foramen lacerum. (C) An even larger view of this area, emphasizing its complex three dimensional structure. 
sinus, the trigeminal ganglion, the petroclival ligament, and the posterior clinoid. Special attention was directed to anatomical structures that limit visualization in this approach. The heads were fixed, in a position, placing the sagittal suture parallel to the floor and the contralateral zygomatic arch in a 45 degrees angle. The craniotomy was performed, while preserving the neural and vascular structures associated with the canal. A 3D model was created, to explain the canal's anatomy.

\section{Results}

The sixth cranial nerve, exits the brainstem, in the anterior aspect of the junction between the pons and the medulla. It has a short tract in the prepontine cistern, and then it enters the clival dura, in between the two layers of this dura. This dural entrance is followed by a sharp turn upwards (the petroclival segment of sixth nerve).$^{11}$ In this interdural plane, it goes up, almost to the level of the petrous ridge, where it

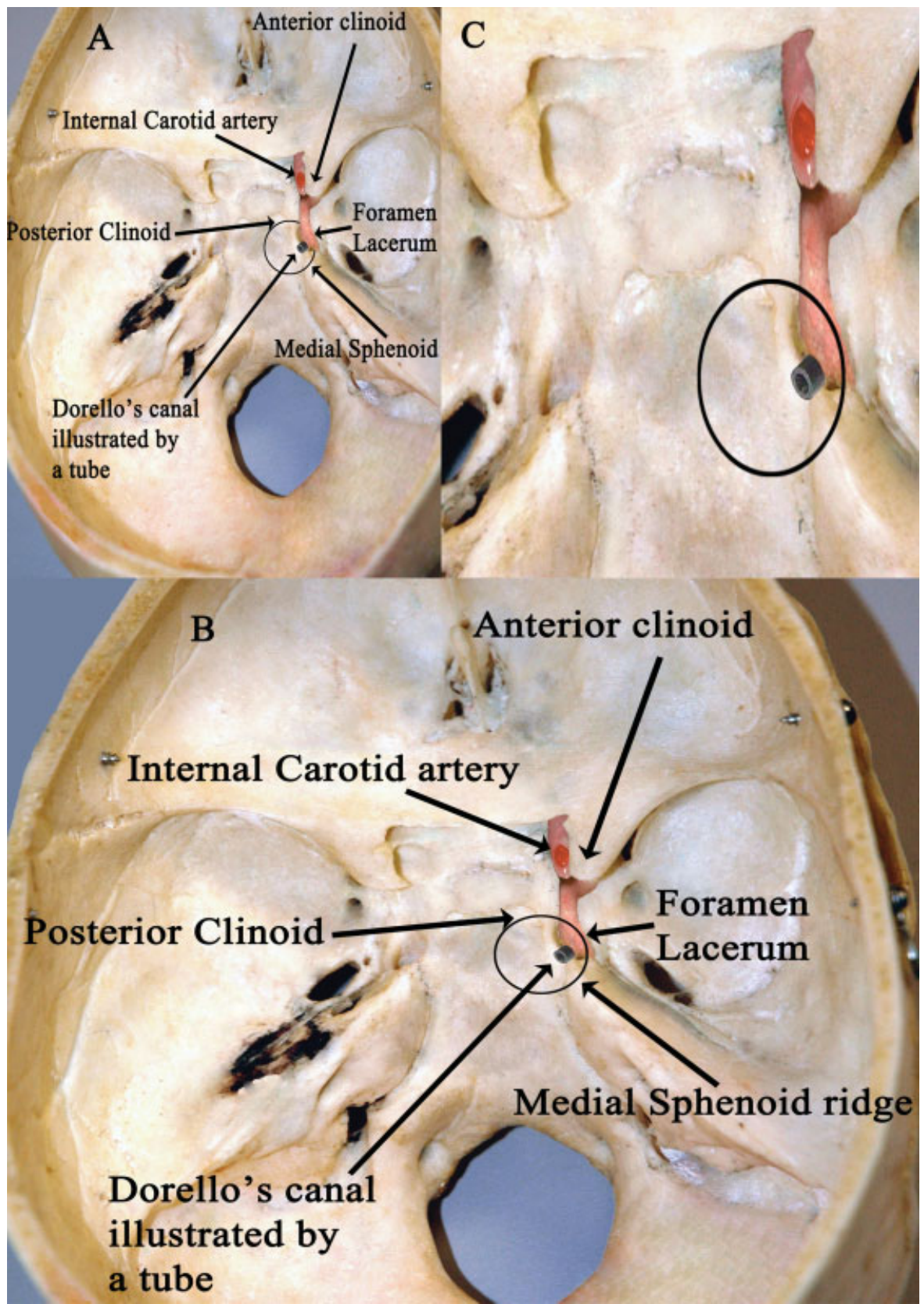

Figure 2 (A) A superior view of the skull base, where the internal carotid artery, has been added, the area between the medial sphenoid wing and the posterior clinoid (Black circle), and Dorello's canal is illustrated by a plastic tube. (B) An enlarged view of the same image, emphasizing the proximity of Dorello's canal to the third part of the internal carotid artery (C3, lateral part). (C) An even larger view of this area, showing that the C3 segment of the internal carotid artery, almost touches the Dorello's canal in this area. 
enters Dorello's canal, beneath Gruber's ligament. Dorello's canal may be simplified, as a canal, between a point below the posterior clinoid and the most anteromedial portion of the petrous ridge. It is 4.0 to $13 \mathrm{~mm}$ in length, and from 0.5 to $3.0 \mathrm{~mm}$ in diameter. ${ }^{5}$ The posteromedial limit of the canal is formed by a ligament, connecting the petrous ridge to the clivus (the petrosphenoidal ligament or Gruber's ligament). The lateral wall is formed by the anteromedial sphenoid ridge and the medial wall by the clivus. The whole canal is embedded inside a venous confluence which occupies the space between the two dural layers (outer or endosteal and inner or cerebral) of the petroclival area. ${ }^{5}$ Once exiting Dorello's canal, the abducens nerve enters the cavernous sinus, and assumes an inferolateral position, with respect to the cavernous carotid. - Fig. 1 depicts a superior view of the skull base. One should pay attention to the posterior clinoid, the medial petrous ridge, and the interval between them, to understand Dorello's canal. This interval ( $\mathbf{- F i g . 1} \mathbf{1}$ ) is the place where the sixth cranial nerve leaves the posterior fossa and enters the middle cranial fossa. This interval is

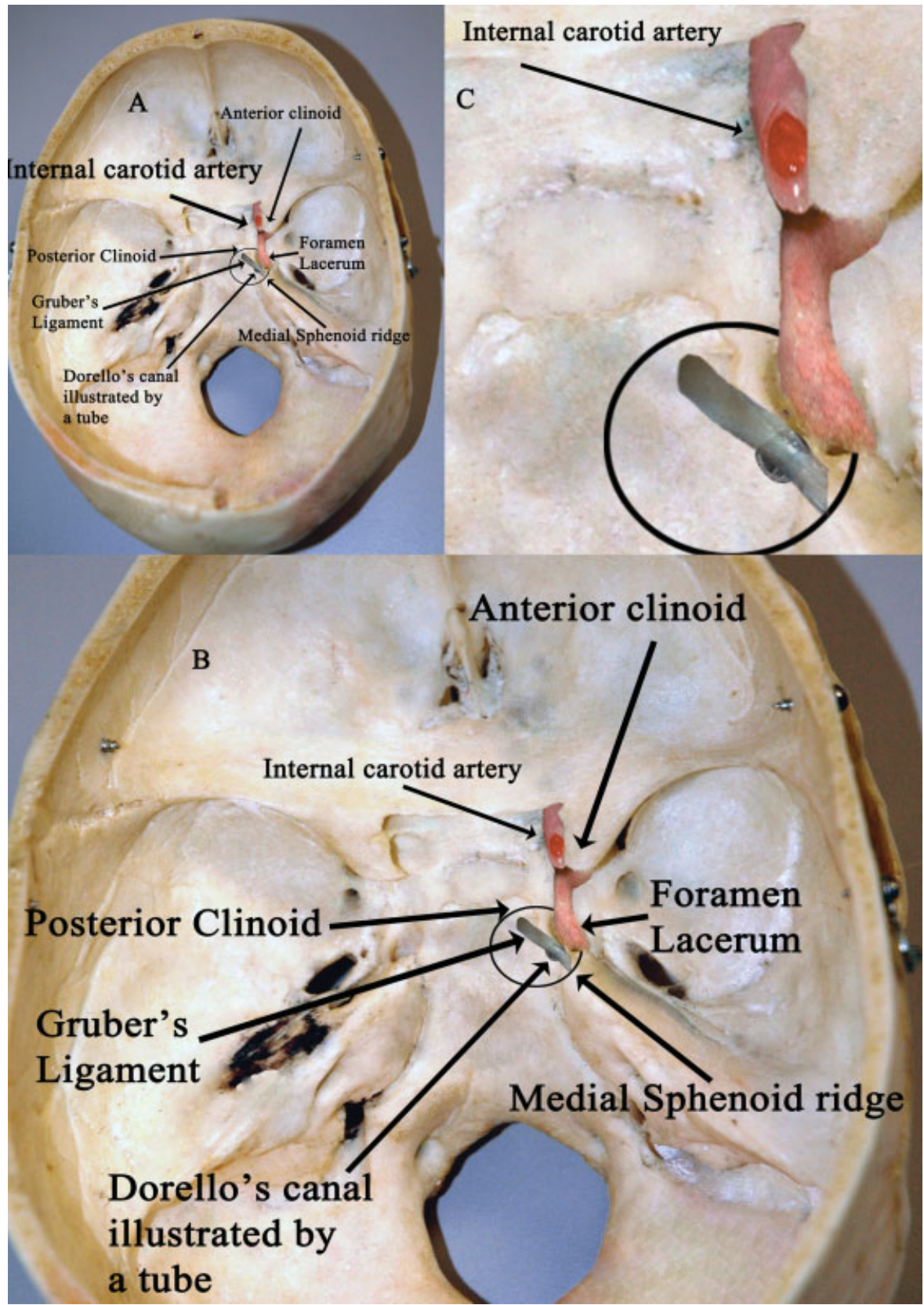

Figure 3 (A) A superior view of the skull base, Gruber's ligament (Petrosphenoidal ligament) was added. This ligament defines the posteromedial wall of the canal extends from the spina sphenoidalis located on the superior border of the petrous apex to the lateral border of the dorsum sellae and clivus, below the posterior clinoid. (B) An enlarged view of the same image, showing that from this angle, Dorello's canal cannot be seen. (C) An even larger view of this area, demonstrating the tract of Gruber's ligament. 


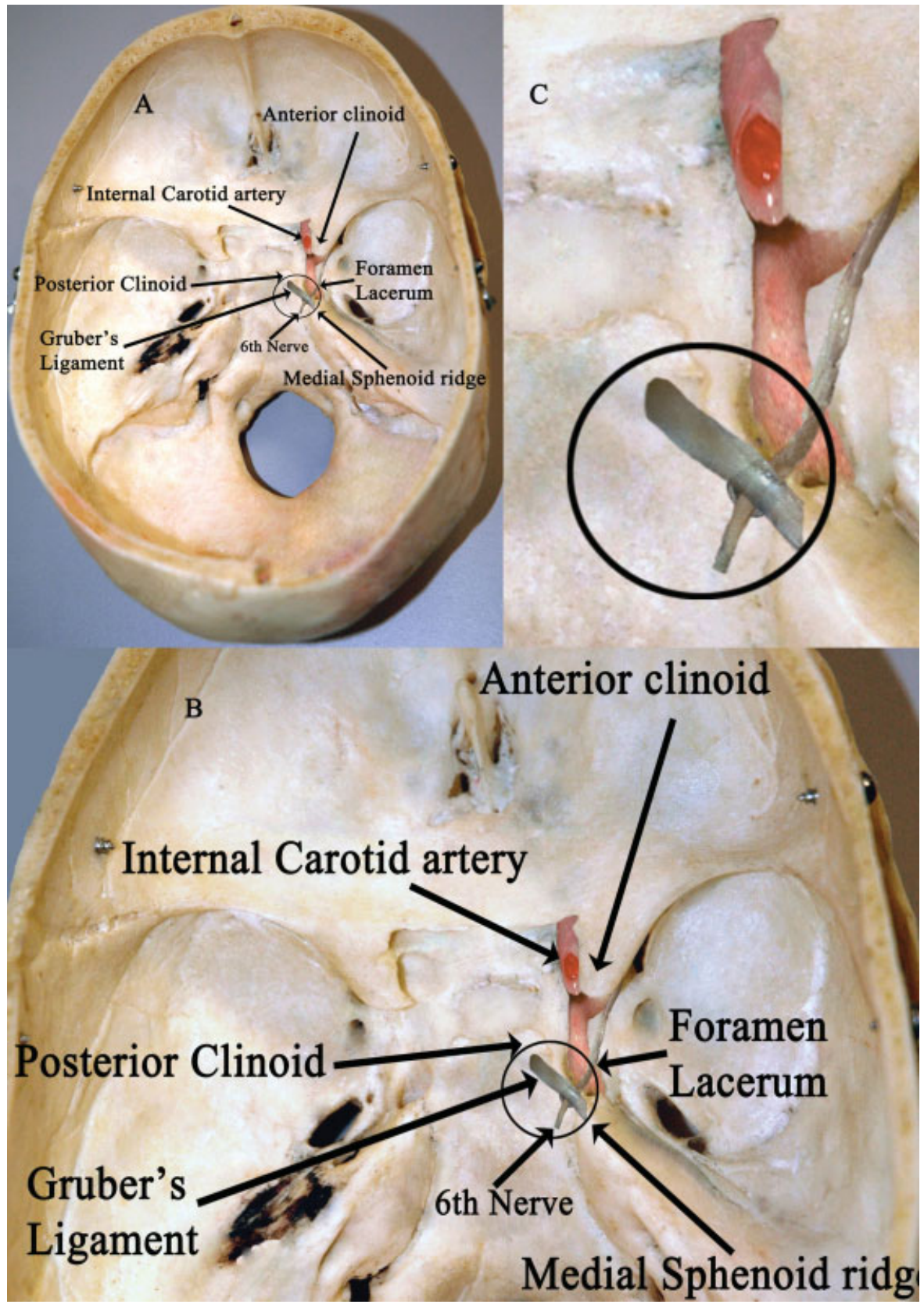

Figure 4 (A) A superior view of the skull base, where the sixth cranial nerve (Abducens nerve), has been added. This nerve enters the middle fossa through Dorello's canal, entering the cavernous sinus. Dorello's canal is illustrated by a plastic tube. (B) An enlarged view of the same image, showing the course of the abducens nerve. (C) An even larger view of this area, showing the relationship between the 6th nerve, Gruber's ligament, the carotid artery, and the anterior clinoid process.

actually where the Dorello's canal is located, housing the abducens nerve, embedded in venous blood. The canal is in direct continuum with the cavernous sinus and it drains its venous blood to the basilar venous plexus.

\section{Discussion}

The reader is encouraged, to follow the sequence of the figures, while trying to reconstruct in his mind each figure, with its added anatomical landmark. One should try to imagine the skull base, and then add in his mind the mentioned building blocks.

The internal carotid artery enters the middle cranial fossa, through the carotid canal, just superior to the foramen lacerum (-Fig. 2). Here, this artery is termed C3, and is in the closest proximity to Dorello's canal. - Fig. 3 adds Gruber's ligament (Petrosphenoidal ligament) to the canal's description. This ligament defines the roof of the canal 


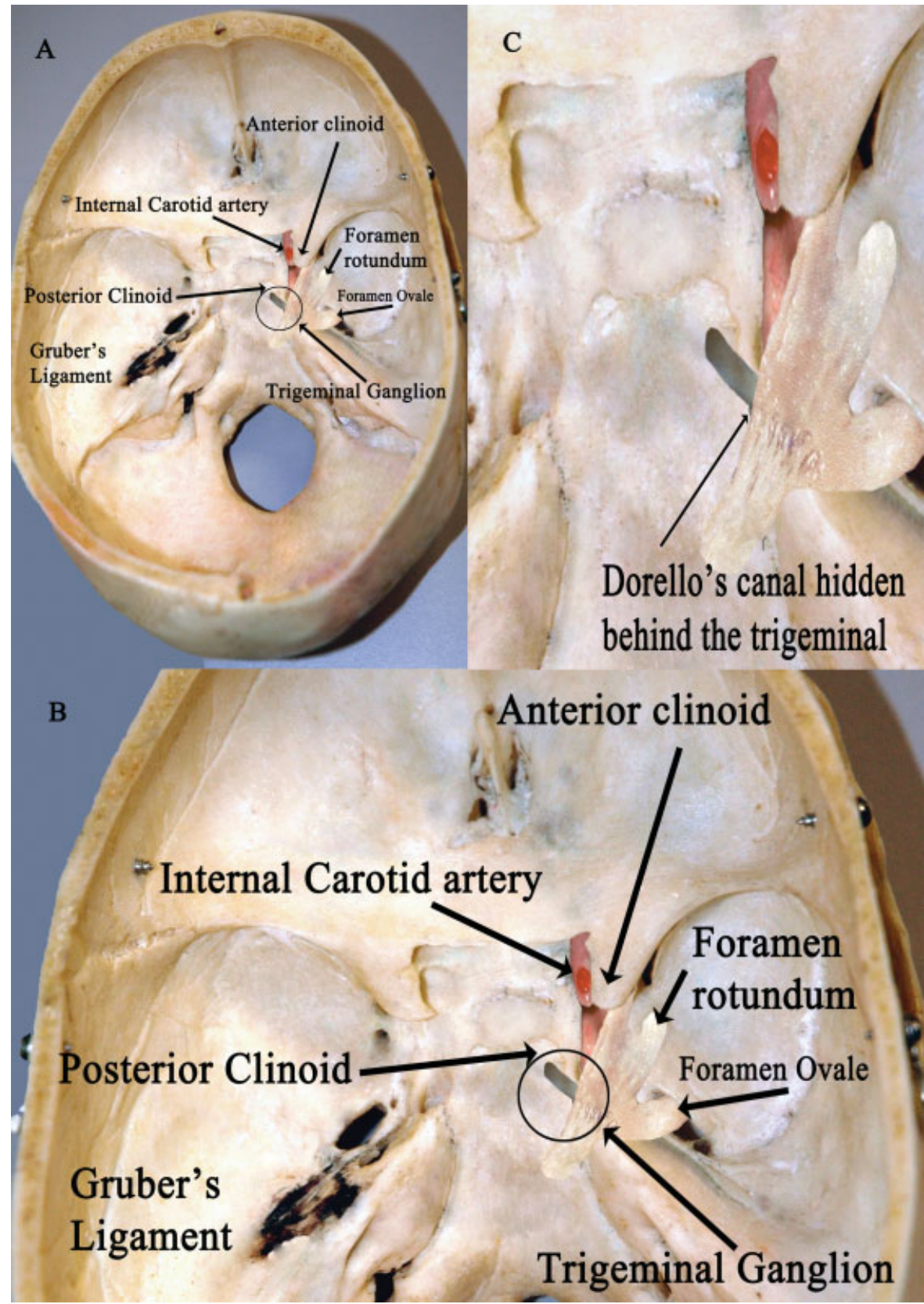

Figure 5 (A) A superior view of the skull base, where the trigeminal (Gasserian) ganglion has been added. (B) An enlarged view of the same image, showing that all the previously mentioned structures are actually hidden medial to the trigeminal ganglion. (C) An even larger view of this area, showing the trigeminal nerve, transversing the trigeminal notch in the sphenoid ridge and entering Meckel's cave.

posteromedially, extending from the spina sphenoidalis located on the superior border of the petrous apex to the lateral border of the dorsum sellae and clivus, below the posterior clinoid. $^{5}$ - Fig. 4 shows the sixth cranial nerve (Abducens nerve), intracranial course. This nerve enters the middle fossa through Dorello's canal, entering the cavernous sinus. Dorello's canal is illustrated by a plastic tube. The relationship between the sixth nerve, Gruber's ligament, the carotid artery, and the anterior clinoid process, is necessary to understand the 3D structure of the canal. - Fig. 5 shows the same structures with the trigeminal (Gasserian) ganglion added. All the previously mentioned structures are actually "hidden" medial to the trigeminal ganglion. - Fig. 6 is a flow chart describing the steps of the added anatomical building blocks.

\section{Conclusion}

The 3D structure of Dorello's canal can be simplified, using five anatomical structures as building blocks. This canal, with its three dimensional structure and relationship to its neighboring anatomical structures could be reconstructed using 


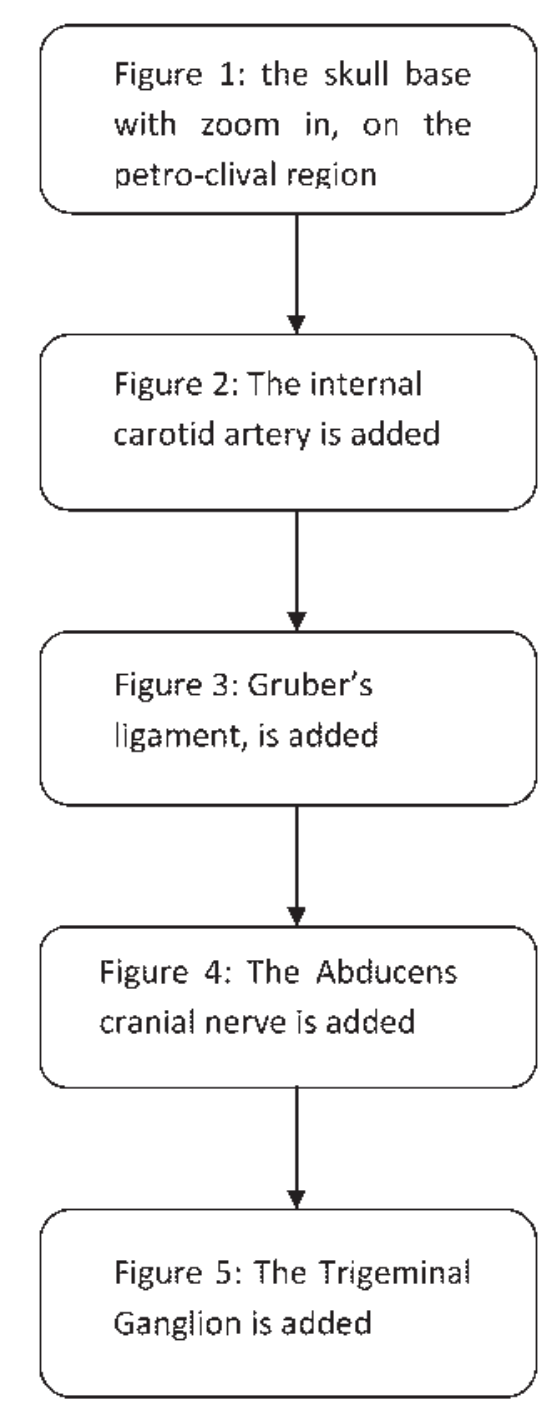

Figure 6 A flow chart describing the steps of the added anatomical building blocks. few anatomical structures. This Lego-like method simplifies the understanding of this complex anatomical structure, and could be used for teaching purposes for aspiring neuroanatomists and neurosurgeons alike.

\section{References}

1 Gruber W. Anatomie des Keilbeins und Schlafenbeins. In: Richter HE, Winter A, eds. Schmidt's Jahrbucher der Und Auslandischen. Gesammten Medicin, II, Anatomie und Physiologie; 1859:40

2 Tsitsopoulos PD, Tsonidis CA, Petsas GP, Hadjiioannou PN, Njau SN, Anagnostopoulos IV. Microsurgical Study of the Dorello's Canal. Skull Base Surg 1996;6(3):181-185

3 Dorello P. Considerazioni sopra la causa della paralisi transitoria dell' abducente nelle flogosi dell' orecchio medio. In: Ferreri G, ed. Atti della Clinica Oto-Rino-Laringoiatrica. Roma; 1905:209-217

4 Vail RL. Anatomical studies of Dorello's canal. Laryngoscope 1922;32:569-575

5 Umansky F, Elidan J, Valarezo A. Dorello's canal: a microanatomical study. J Neurosurg 1991;75(2):294-298

6 Destrieux C, Velut S, Kakou MK, Lefrancq T, Arbeille B, Santini JJ. A new concept in Dorello's canal microanatomy: the petroclival venous confluence. J Neurosurg 1997;87(1):67-72

7 Liu XD, Xu QW, Che XM, Mao RL. Anatomy of the petrosphenoidal and petrolingual ligaments at the petrous apex. Clin Anat 2009; 22(3):302-306

8 Yousry I, Camelio S, Wiesmann M, et al. Detailed magnetic resonance imaging anatomy of the cisternal segment of the abducent nerve: Dorello's canal and neurovascular relationships and landmarks. J Neurosurg 1999;91(2):276-283

9 Ozveren MF, Erol FS, Alkan A, Kocak A, Onal C, Türe U. Microanatomical architecture of Dorello's canal and its clinical implications. Neurosurgery 2007;60(2, Suppl 1):ONS1-ONS7, discussion ONS7-ONS8

10 Sanan A, Abdel Aziz KM, Janjua RM, van Loveren HR, Keller JT. Colored silicone injection for use in neurosurgical dissections: anatomic technical note. Neurosurgery 1999;45(5):1267-1271, discussion 1271-1274

11 Tekdemir I, Deda H, Karahan ST, Arinci K. The Intracranial Course of the Abducens Nerve. Turk Neurosurg 1996;6:96-102 